\title{
Toward Characterization of Huber's Ball-Bearing Motor
}

\author{
Joo L. Choo ${ }^{1,2}$, Wen L. Soong ${ }^{2}$ and D. Abbott ${ }^{1,2 \#}$ \\ ${ }^{1}$ Centre of Biomedical Engineering (CBME), The University of Adelaide, \\ Adelaide, SA 5005, Australia. \\ ${ }^{2}$ School of Electrical and Electronic Engineering, The University of Adelaide, \\ Adelaide, SA 5005, Australia.
}

\begin{abstract}
A motor that can be powered up by either a DC or AC supply and rotates in either direction, based on the so-called Huber effect, is investigated. For the first time, this paper examines the motor characteristics under both DC and AC conditions, for quantitative comparisons. Earlier work has not examined, in detail, the effect of an AC supply on the Huber motor operation. Previous work on the Huber or ball-bearing motor suffered from alignment problems and here we describe a new methodology to address this. The new construction is also a step toward a micromotor realization. The motor, with its reduced dimensions, also has the advantage of reduced operating current. Since 1959, the principle of operation of this motor has remained an unsolved mystery and various theories exist in the literature. We show various empirical findings that shed some light on the hotly contested debate. The discovery of carbon on the bearings, under AC supply conditions, reported here creates a new open question. Motor acceleration versus torque characteristics are obtained, using a data acquisition system to facilitate dynamic real-time recording.
\end{abstract}

Keywords: Huber effect, Ball bearing motor, Micromotor.

\section{INTRODUCTION}

A motor based on the Huber effect is known as the Huber motor or the ball-bearing motor. The Huber effect is a phenomenon, of hitherto unknown origin, named after J. Huber ${ }^{1}$ in 1959. Huber discovered that he could propel a pair of conducting wheels along a set of rails, by passing a large current through the assembly.

Milroy $^{2}$ first used a ball-bearing motor construction, to illustrate the Huber effect, in which the motor consists of a metal shaft with both ends mounted with a set of ball bearings, as shown in Fig. 1. Whether AC or DC is passed through the assembly, and coupled with an initial starting torque, the shaft will continue rotating in the direction of the initial starting torque.

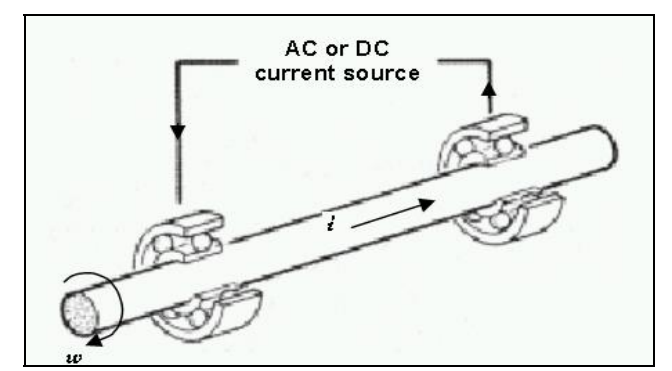

Fig. 1: Ball bearing motor assembly. Supplied current $i$ resulting in angular rotation, w. After ref. [3].

In an earlier paper, by Lauterbach ${ }^{4}$ et al., which investigated small Huber motors, it was pointed out that the poor performance characteristics of large Huber motors is due to the large amount of current required, producing heating and rapid deterioration - a key finding was that the required amount of current scales down with a corresponding reduction in motor size. This raises an interesting issue for Microelectromechanical Systems (MEMS) technology that could potentially exploit the Huber effect, once it is fully understood.

Corresponding author: ${ }^{\#}$ dabbott@eleceng.adelaide.edu.au; Telephone: +61-8-8303-5748; Fax: +61-8-8303-4360 


\section{EARLIER HYPOTHESES}

Since its discovery in 1959, many workers have put forward theories about the physical origin of the Huber effect. In spite of many experiments, based on these theories, there is no conclusive experimental evidence to conclusively refute or support either one. Thus the fundamental theory on the origin of Huber effect remains unknown. Among the theories put forward, three main hypotheses are discussed here.. They are (i) the electromagnetic force effect, (ii) the thermal expansion effect, and lastly, (iii) the plasma discharge effect.

\subsection{Electromagnetic effect hypothesis}

Gruenberg $^{3}$ first proposed an electromagnetic force as the cause for the Huber effect. His analysis considered a single ball bearing in contact with both the inner and outer races. This single ball has a primary volume current density $\mathbf{J}_{0}$ and a primary magnetic field $\mathbf{B}_{0}$ due to the flow of electric current between the inner and outer races. Under the assumption that the ball rotates with angular velocity $\omega$, a secondary volume current density $\mathbf{J}_{1}$ will be induced as a result of the motion displacement experienced in the primary magnetic field $\mathbf{B}_{0}$. A new charge is produced together with an associated electric field $\mathbf{E}_{1}$ and magnetic field $\mathbf{B}_{1}$. For a repeated process, for the translational velocity, the interactions of the induced current with the $\mathbf{B}_{0}$ field will produce only radial forces. The result of interactions between $\mathbf{J}_{0}$ and $\mathbf{B}_{1}$, and $\mathbf{J}_{1}$ and $\mathbf{B}_{0}$ have a large contribution to the torque. When the motor starts running, it develops a rotational torque in the direction of $\omega$ and has no starting torque. This theory was extended using Maxwell's equations and it predicted the torque is directly proportional to the angular velocity and square of the current:

$$
T=k \cdot \omega \cdot i^{2}
$$

where $T$ is the torque developed, $k$ is the physical property constant of the ball, $\omega$ is the angular velocity and $i$ is the motor supply current. The relationship between speed and current is determined to be:

$$
i^{2}=a+b \cdot \omega
$$

where both $a$ and $b$ are constants (see Fig. 2).

Initially, these relationships were suggested algebraically incorrect by Weenink ${ }^{5}$ but subsequently supported by Moyssides and Hatzikonstantinou ${ }^{6-9}$. They calculated that the first- and second-order torque of the ball is zero, and later evaluated that the third-order torque is zero as well. Moyssides and Hatzikonstantinou concluded that the forces from the interactions of the currents and magnetic fields within each ball do not produce any form of torque as suggested by Gruenberg ${ }^{3}$.

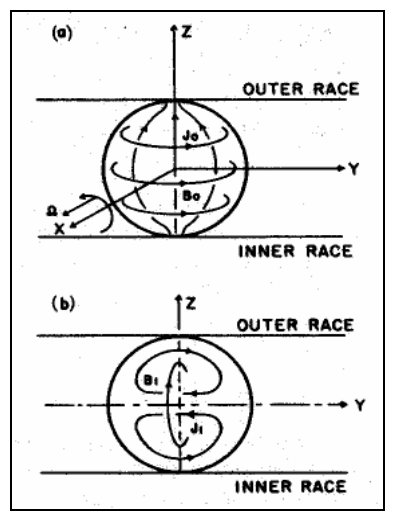

Fig. 2: Current and field distribution in ball. (a) Zero-order fields. (b) 1st-order fields. After ref. [3].

Moyssides and Hatzikonstantinou therefore present a slightly varied theory based on the interactions of the supplied current, induced currents, and magnetic fields developed within the balls (see Fig. 3). In the preceding figure with its associated coordinate system, the stationary ball is set into rotation with a push and this ball is subjected to a torque resulted from the excited force, $F$ : 


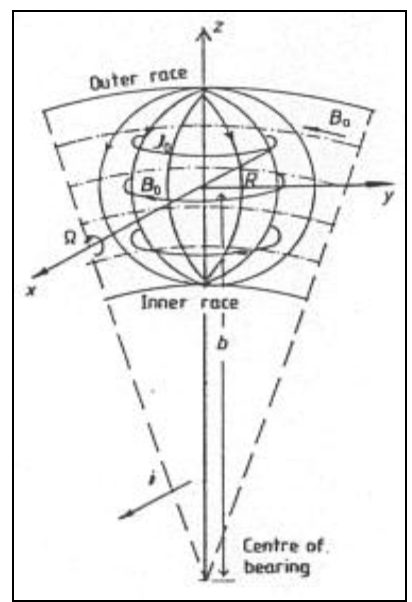

Fig. 3: Current and fields of a non-rotating ball: $\Omega$ is the angular velocity; $J_{0}$ is the primary current density; $B_{0}$ is the magnetic field of the current $\mathrm{J}_{0} ; B_{a}$ is the magnetic field generated by the current $i$ of the central axis; $R$ is the radius of the ball. After ref. [9].

$$
F=J \times B
$$

where $J$ is the volume current density in rotation, and $B$ is the magnetic field associated with the primary current in the vicinity of and inside of the ball. These induced currents and magnetic fields present the result of the complicated electromagnetic structure within a ball. The result concurs with the square law equation in (1) for the torque of the ball bearing motor and the non-linear speed current relationship. Moyssides and Hatzikonstantinou ${ }^{6}$ in addition calculated that the current is non-linearly dependent on the angular velocity:

$$
i=a+b \omega+c \omega^{2}
$$

where $a, b$ and $c$ are constants. Watson, et $a l .{ }^{10}$ predict a non-linear current similar to that presented by Moyssides and Hatzikonstantinou. With an increase in supply current, the resulting angular velocity of the ball bearing motor also increases - but the increased current produces heating. The rise of temperature in the ball bearing motor system causes physical expansion of the balls. The contact friction of the ball against both inner and outer races increases and a decrease of angular velocity of the ball bearing motor is then experienced. Eventually the ball bearing motor jams to a halt, due to excessive frictional forces acting on the ball bearings. The experimental results obtained by Watson et al. ${ }^{10}$ found a linear relationship between the no-load speed and current and this refutes the above square law expression for the speed-current characteristics. Nevertheless, Watson et al. ${ }^{10}$ results correspond with Gruenberg's prediction of low motor efficiency. The experimental results also tallied with the prediction that efficiency increases with dimensional size of the motor.

\subsection{Theory of thermal expansion}

The theory of thermal expansion was instigated by Marinov" stating that "the ball bearing motor is not an electromagnetic motor but a thermal engine." According to this theory, the physical expansion of each ball bearing is the main cause of rotation. The contact point, between the ball bearing and the races, possesses a higher ohmic resistance than that across the ball bearing. This is the point where the ball bearing heats up most and a physical dilation of the ball bearing is experienced. The dilation of the ball bearing causes it to bulge and with an initial rotational torque, the motor will rotate in the given direction of the initial rotational torque. The motor sustains its rotational movement through its repeated heating of ball bearing contacts coming into electrical contact with the races with every rotational movement.

There is a notable lack of explanation regarding the relatively long time thermal constants in most systems. Given the high Huber motor rotation rates, in the order of thousands of rpm, this would seem to place some doubt on Marinov's thermal expansion theory. 


\subsection{Theory of plasma discharge}

In 1973, Polivanov, et $a l^{12}$ emphasized that plasma discharge was a large contributor to the Huber effect. This discharge takes place between the surfaces of the ball bearing and its races, and it produces a force sufficient to maintain rotation. This force is generated by the induced EMF, which has a tendency to cause a current to flow in a direction opposing the direction of the induced EMF. It is the interaction of these induced currents within the magnetic field that causes a disturbance to the symmetry of the current and flux distribution established by previous contact points. With a point of contact being established continually in rotation, the force is sustained. This continual process is illustrated in Fig. 4.

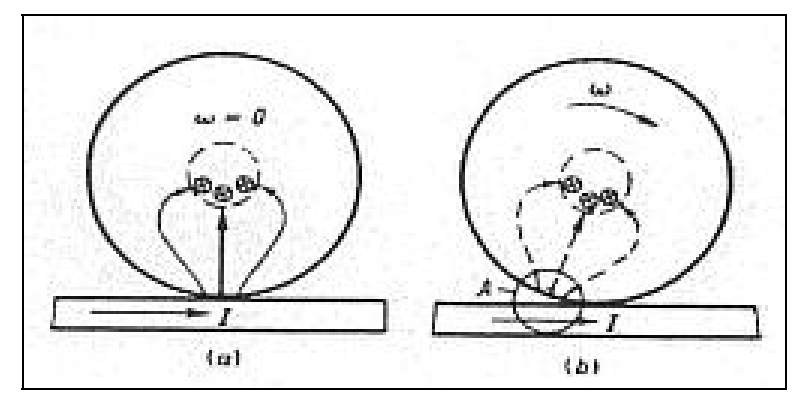

Fig. 4: (a) Spread of current in the cross-section of a stationary ball. (b) New current distribution when the ball is rotated. After ref. [12].

In Fig. 4, rotation causes the establishment of a new point of contact. This develops a new current distribution due to the disturbance experienced in the symmetry of both the current and flux distribution. Hence the rotation of the motor shaft is sustained by the momentum of the occurrence of plasma discharge. Netushil ${ }^{13}$ reviewed the explanation presented earlier and arrived at an expression for the force being repelled from the surface of the races:

$$
F=k \cdot i^{2}
$$

where $k$ is a constant dependent on the materials of the surface and the form of arc discharge $\left(3 \times 10^{-7} \leq k \geq 6.5 \times 10^{-7}\right)$.

\subsection{Previous experimental results}

Ball bearing motor experiments were carried out by Thompson, et al. ${ }^{14}$ in 1999 . Two different prototypes of the ball bearing motor were constructed. One had a brass tube attached to the exterior of the ball bearing races, while the other had a solid brass rod fixed to the interior of the ball bearing races. The latter prototype proved to have lesser friction, and hence require lower starting current. Experimental results obtained were still insufficient to conclusively establish correctness of any of the above theories. The following year, Lauterbach et al. ${ }^{4}$ made significant improvements to the construction of the ball bearing motor. Two ball bearing motors were constructed with different dimensions while retaining the use of the interior shaft. Although the larger of the motors, is more difficult to properly characterize, it facilitates experiments of the various concepts behind the Huber effect. The other miniature motor was used to promisingly characterize the Huber effect in terms of its torque and speed. This work showed promise, but the results were still insufficient for conclusively determining the mysterious origin of the Huber effect.

\subsection{Power supply}

\section{EXPERIMENTAL APPARATUS AND METHODOLOGIES}

Earlier experiments conducted had to connect together several commercial power supplies, in order to achieve the necessary DC output current. Furthermore, experiments on AC current were not previously conducted.

The power supply is constructed using a transformer followed by a full-wave bridge rectifier. The power supply is capable of producing 0-7 Volts open-circuit and a load current of between 0-60 Amperes. Capacitors were required to further reduce the ripple effect, to smooth the current. The power supply is connected to a variac, which is in turn connected to the mains $(240 \mathrm{~V})$ for turns ratio variations. A large heat sink and cooling fan is built in to the power supply for heat absorption and to assist in heat elimination of components therein. 


\subsubsection{Frequency variation of power supply}

The frequency of the AC supply is varied by using a transistor switching technique, through the use of a high volt-amps power transistor module. A proper heat sink was used for the mounting of this transistor module. A DC supply was fed to the collector-end of the transistor module, while the emitter was connected to the Huber motor. The base of the transistor was connected to signal generator which would generate a switching signal of varying frequencies.

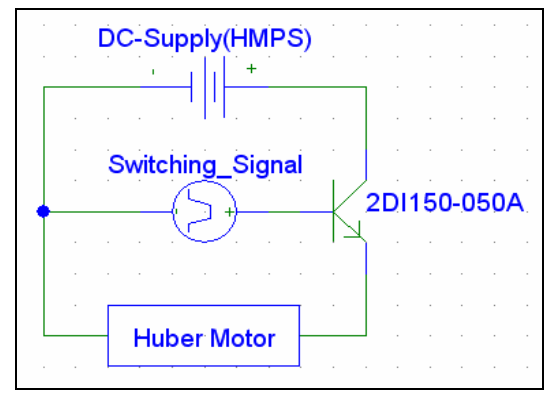

Fig. 5: Frequency variation module. A DC supply was connected to the collector-end with the emitter-end to the Huber motor. The base was connected to the signal generator to vary the frequency of the supply source via switching.

\subsection{Ball bearing motor}

\subsubsection{Existing ball bearing motor and its modifications}

The ball bearing motor is made up of two ball bearing races and a shaft. Current is injected to the motor via the two races, and rotary movement is experienced with an application of initial torque. Modifications are made to the ball bearing motor, from previous efforts, by drilling more holes into the spacer between the two races. This allows more kerosene to flow into the motor and will result in better heat sinking effect (see Fig. 6). Bearings are monitored for degradation and new bearings are regularly replaced after deterioration. The calculation of moment of inertia for the shaft of the existing motor is determined to be $233.6 \times 10^{-9} \mathrm{~kg} \cdot \mathrm{m}^{2}$.

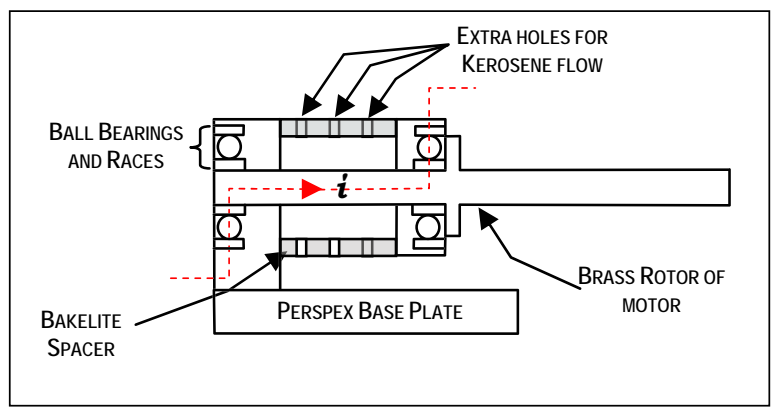

Fig. 6: Cross-sectional view of Ball Bearing motor. Extra holes were bored into the spacer between the two bearing races for more kerosene flow.

\subsubsection{Miniature ball bearing motor}

The slightest misalignment of the shaft and bearing races results in a substantial frictional force for the motor to overcome. A significant breakthrough in the reduction of alignment errors is described, for the first time, in this paper. The adoption of the single process of boring through a solid piece of bakelite was the first step in eliminating unnecessary misalignment due to assembly procedures. Bakelite was used due to its high deforming-resistance to high temperature during motor operation. A hole was bored through the central axis of the bakelite cylinder, and the races made a push-fit in either end. Two screws were radially threaded through the bakelite on each end to provide an 
electrical contact for the races. These two screws upon contact with the outer race on each end form a conducting link with the brass shaft attached to its inner race (see Fig. 7).
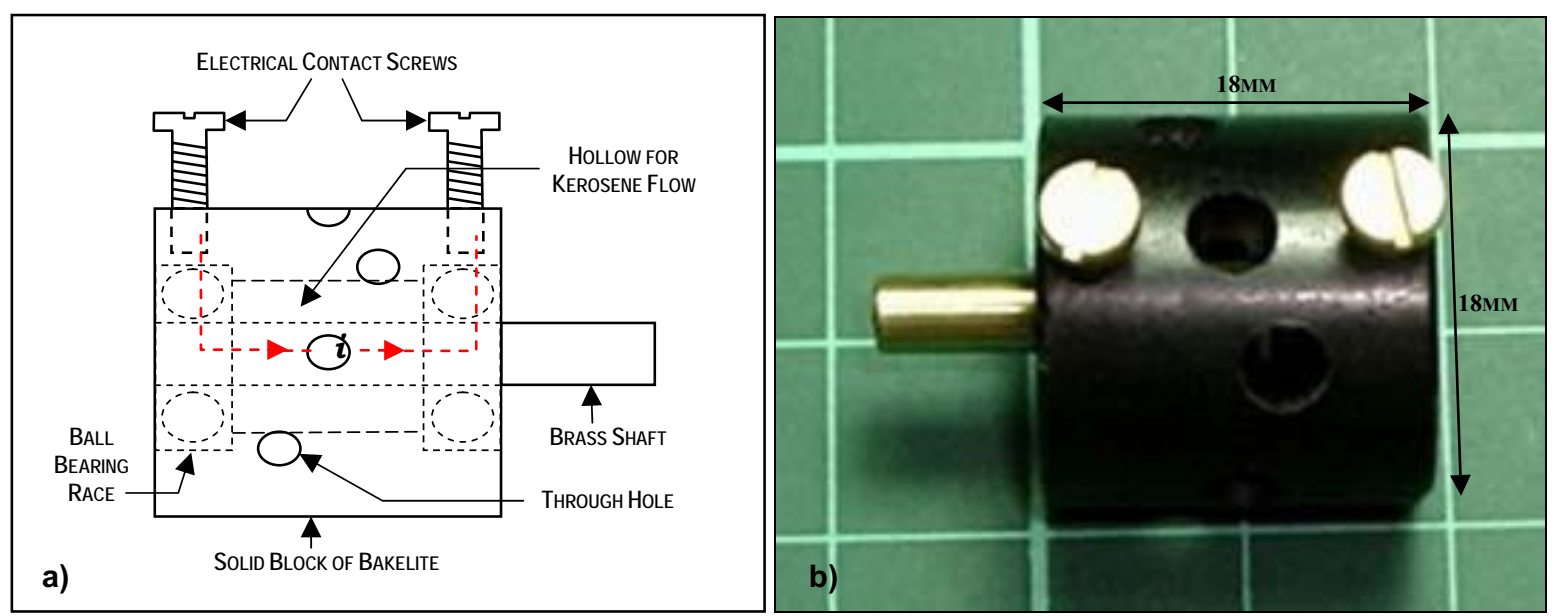

Fig. 7: a) Front Elevation View. Holes created in the bakelite block facilitate the inflow of kerosene to allow liquid cooling during operation. The exterior brass shaft allows the mounting of an optical codewheel. b) Close-up photographic view of the miniature ball bearing motor.

An extension for the shaft was constructed in order for the motor to submerge fully in the kerosene bath. The calculation of moment of inertia for the shaft of the miniature motor was determined to be $37.4 \times 10^{-9} \mathrm{~kg} \cdot \mathrm{m}^{2}$.

\subsubsection{Micro ball bearing motor}

Improvements are further achieved with higher-grade instrument ball bearings races. The diameter of the inner bearing race is $3.175 \mathrm{~mm}$, while the shaft gap between races is about $4 \mathrm{~mm}$. The diameter of exterior portion of the shaft remains at $4 \mathrm{~mm}$ to accommodate mounting of the optical codewheel. In addition, the bearing race is fitted into a circular brass brace to prevent bearing race distortion made by variations in the tightness of the screws. This reduced-size motor results in a lower current requirement and thereby increases the level of repeatability for experiments (see Fig. 8). Low currents are important for repeatability, as higher currents cause overheating and deterioration, leading to poor motor characterization.
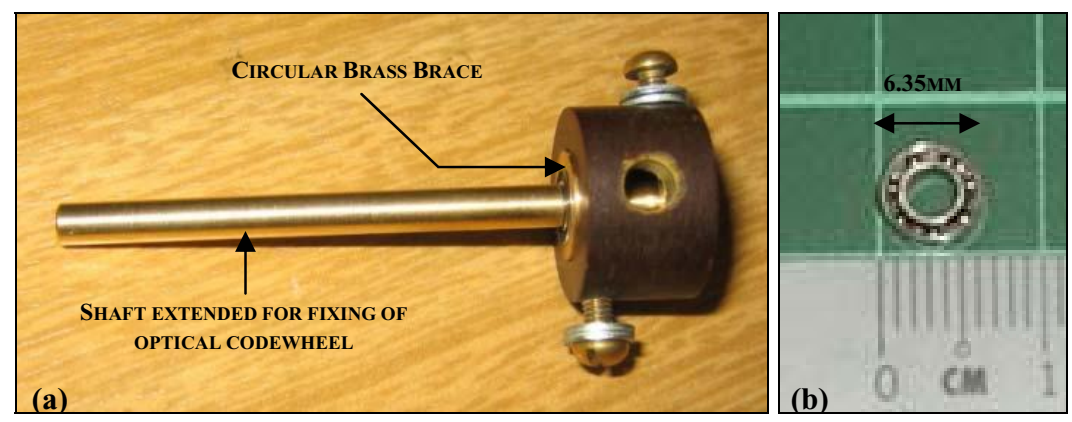

Fig. 8: (a) Micro ball bearing motor. Shaft gap between both bearing races is a small as $4 \mathrm{~mm}$. The circular brass brace eliminates distortion caused by the tightening of the screws. Contact screws were placed on opposing sides due to the short length of the bakelite. (b) Diameter of ball bearing outer race is $6.35 \mathrm{~mm}$, while its inner race is of $3.175 \mathrm{~mm}$ wide.

The shaft of the micro ball bearing motor is constructed as a single entity and the calculation of moment of inertia for the shaft of the micro motor gives: $8.6 \times 10^{-9} \mathrm{~kg} \cdot \mathrm{m}^{2}$.

\subsection{Torque properties of the Huber motor}


The total torque for the Huber motor consists of the acceleration torque as well as the frictional torque generated when in operation. This total torque can be expressed as:

$$
T_{\text {Total }}=T_{\text {Acceleration }}+T_{\text {Frictional }}
$$

The acceleration torque can be determined from the differential of angular velocity with respect to time and the moment of inertia, $J$, for the rotating shaft. This acceleration torque can be expressed as:

$$
T_{\text {Acceleration }}=J \cdot \frac{\partial \omega}{\partial t} .
$$

The moment of inertia, $J$, is calculated from the dimensions of the rotational shaft. The ball bearings and its races are assumed to have negligible effect. The angular velocity, $\omega$, considered here begins from zero, until the steady-state is arrived with its corresponding time characteristic. The frictional torque for the Huber motor is determined with the use of a conventional DC motor. With the back EMF constant, $k$, for the DC motor characterized, the torque is determined as in Equation 8 with a known value of armature current,

$$
T=k . I_{\text {Armature }}
$$

With the load (Huber motor) connected to the DC motor, the system torque for the two connected together is the summation of the inherent Huber torque and torque of DC motor. Therefore, the inherent Huber torque produced can be expressed as:

$$
T_{\text {Inherent }}=T_{\text {System }}-T_{\text {DCmotor. }}
$$

Torque values for the DC motor for (i) no load, (ii) inactive, and (iii) active loads is determined. This facilitated the determination of the inherent Huber torque. Consequently, the total Huber torque produced by the ball bearing motor is the summation of the corresponding acceleration torque and inherent Huber torque.

\subsection{Angular velocity measurement}

\subsubsection{Detection component}

The angular velocity of the Huber motor is determined with the employment of an optical encoder and its codewheel. The codewheel is fixed onto the rotating shaft and a portion of its optical radius is placed between the emitter and detector of the optical encoder module. The encoder module produces a digitized result based on the frequency of detected light passing through the codewheel. This digital output of the encoder module is converted into analog values for data acquisition using the LabVIEW Data Acquisition Module.

\subsubsection{Frequency-to-voltage converter}

For LabVIEW to perform its data acquisition, the input to the DAQ card must be in analog form and limited to a maximum voltage rating of $5 \mathrm{~V}$. The Frequency-to-Voltage Converter circuitry converts an input square wave signal (digital output of encoder module) to a pulse width modulated signal dependent on the input frequency. A low pass filter is then designed to produce a linearly varying voltage, dependent upon the pulse width modulated signal. With speed calibration data, the angular velocity of the motor can be determined from the voltage obtained,

$$
f=\frac{n N}{60}
$$

where $f$ is in the input frequency of the square-wave signal, $n$ is the speed of rotation, and $N$ is the resolution of the optical codewheel.

\subsection{Magnetic fields of large ball bearing motor}

Observations of electromagnetic flux lines and directional indications are carried out. First, the large ball bearing motor is set in operation with a piece of paper scattered with iron filings held firmly over it. With slight tapping on the edges of the paper, the iron filings form patterns induced by the magnetic fields generated by the currents through the motor. A directional compass is also used to confirm the polarities the magnetic fields generated. The compass is positioned at 
various points around the rotating motor for directional observations. The placement locations for the compass are indicated by dots in Fig. 9(a), with the figure viewed from the top. In addition, the ball bearing motor is elevated off the laboratory table for the compass to be repeatedly positioned underneath the rotating motor for observations on the directional effects. Tests are iterated for both different directional rotations and current flow into the motor.
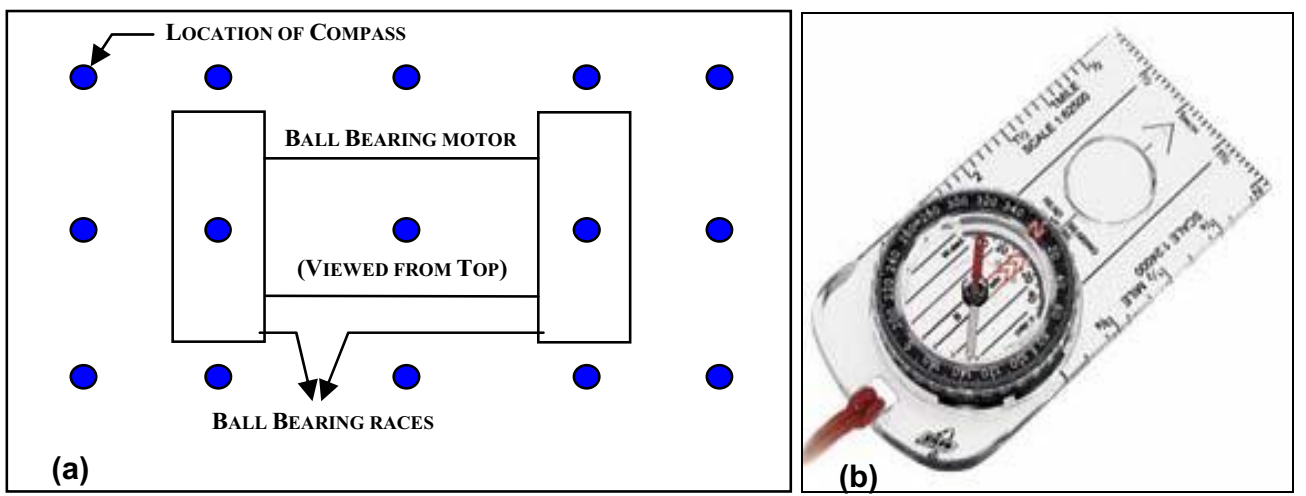

Fig. 9: (a) Compass positions indicated by blue dots located around the motor viewed from the top. (b) Directional compass used in experiment. Red arrow indicates North direction.

\subsection{Huber motor operation in vacuum environment}

The primary objective of vacuum environment experimentation is to attempt test the plasma discharge theory, as the main contributor to the sustainable rotational force in the motor. An enclosed tube made from Perspex was constructed for housing the Huber motor. The use of a water aspirator connected to the enclosed tube creates a vacuum environment in the tube for the experiment. If the plasma discharge theory is true, then by evacuating the air from the chamber, we expect the motor to grind to a halt or at least dramatically slow down. The vacuum within the Perspex tube is created with the water aspirator drawing out air from the tube via its inlet. The pressure gauge indicates the amount of pressure below atmospheric level within the tube in inches of mercury.
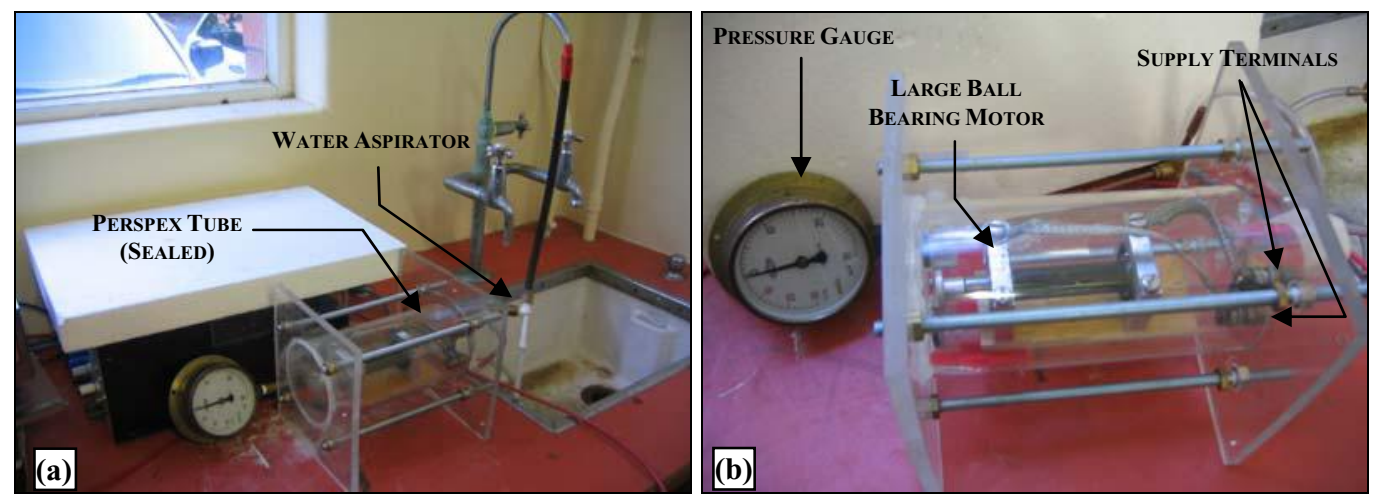

Fig. 10: (a) Vacuum environment test setup. Pressure gauge is connected to the water aspirator, while the aspirator is connected to the running tap for test in operation. (b) Ball bearing motor resides in the Perspex tube with its races supplied with current via cables from supply terminals.

\section{EXPERIMENTAL RESULTS}

\subsection{Findings on magnetic fields of large ball bearing motor}

\subsubsection{Magnetic fields}

The observations of magnetic fields for the motor are conducted for an AC supply source and this is repeated twice. Both plots of iron filing patterns, induced by the magnetic field, from the rotating motor are similar. With the AC supply, the magnetic field pattern is also observed on the cables attached to the motor supply terminals. The illustrations in Fig. 11 
are patterns indicative of the paths induced by the magnetic fields generated by the motor. The magnetic field is observed to be most intense on both ends of the supply terminals. It is also observed that there are significant magnetic fields between the two supply terminals, and the effect diminishes as we move away from the motor.
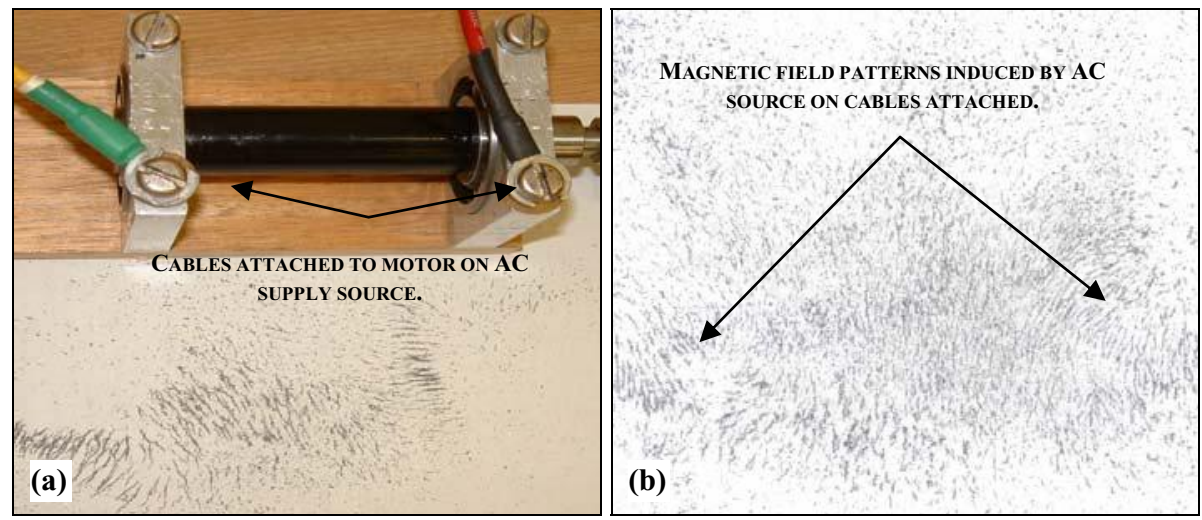

Fig. 11: (a) Magnetic field patterns induced by the rotating motor $-1^{\text {st }}$ test. Motor was placed directly below paper during conduct of test in the above orientation. (b) Scanned image of magnetic field patterns induced by the rotating motor $-2^{\text {nd }}$ test. Motor placement under the paper was identical to that explained for Fig.12 (a).

\subsubsection{Magnetic directions}

The use of a directional compass indicates the change in magnetic directions effected from the magnetic fields generated by the motor in operation. The compass, when held in positions as described in Fig. 9(a), results in no deflection of compass needle when no power is supplied to motor. However, once the motor is supplied with either DC or AC power, the compass needle deflects with reference to the direction of current flow, as in Ampere's right-hand rule ${ }^{15}$.

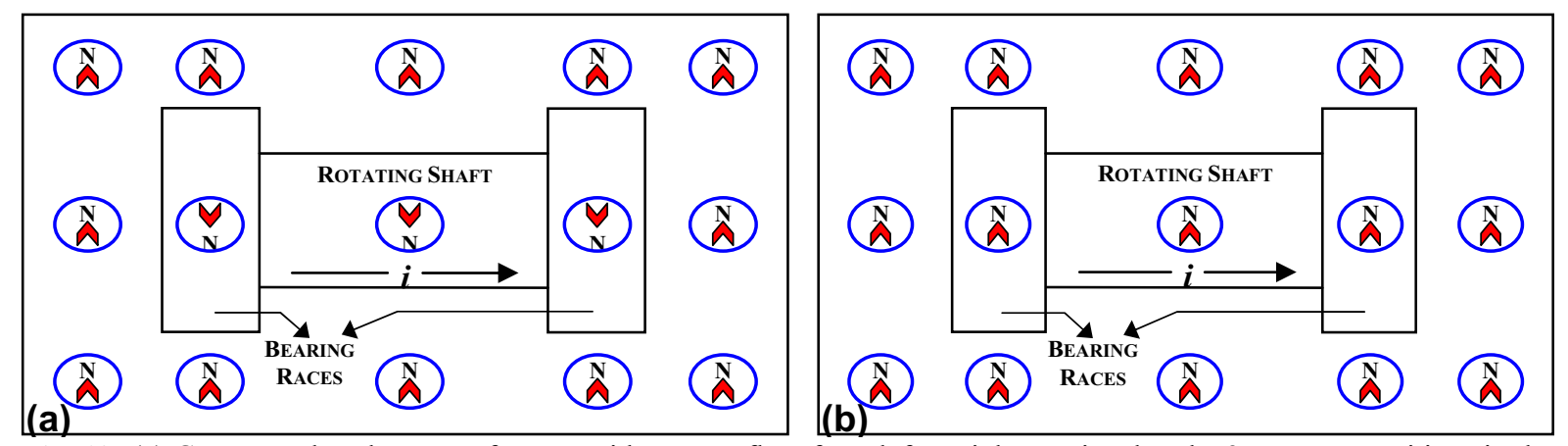

Fig. 12: (a) Compass placed on top of motor with current flow from left to right. Notice that the 3 compass positions in the centre of the plot have a $180^{\circ}$ deflection based on right-hand rule. (b) Compass placed below motor. Comparing with figure 12(a), the 3 compass positions, which had deflected by $180^{\circ}$, are back to their original state.

The figure below (Fig. 13) indicates the flow of current into the conducting shaft and the resulting magnetic field of the conductor; viewed shaft-end was as illustrated. This illustration fully corresponds to the deflections found by the compass in the surrounding space of the rotating shaft shown in Fig. 12(a) and (b).

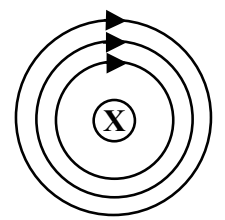

Fig. 13: (X) indicates current flowing into the shaft-end of the motor, and the magnetic directions in the surrounding space are as illustrated. After ref. [15]. 
The directions of the compass needle encounter a $180^{\circ}$ flip, when the current is reversed, regardless which direction the motor rotates. Thus the magnetic directions of the motor are observed to be uniform with reference to the direction of current.

\subsection{Findings of Huber motor operation in vacuum environment}

The experiment is conducted initially in a brightly lit environment, for observations on the motor in vacuo. The pressure in the sealed Perspex tube is about 81.27 kilopascals below atmospheric pressure, as indicated by the pressure gauge. During the experiment, we observe occasional ball bearing motor self-starting. Self-starting was also observed by Marinov, ${ }^{11}$ although he drew physically incorrect conclusions from this. During motor operation in vacuo, we observe no visual signs of arcing or sparks. No degradation of motor performance is observed in the vacuum chamber, and the motor does not speed up as the vacuum is gradually released back to atmospheric pressure. We repeat this test in total dark conditions, and find no evidence of sparking. This appears to refute the claims by Netushil, et $a l^{12,13}$ for the plasma discharge as the main contributor to the motor in sustaining its rotational motion.

\subsection{Speed characteristics}

There are three different motors used in our experiments. They are (i) the existing ball bearing motor from previous work, by Lauterbach, (ii) the miniature and (iii) micro ball bearing motors from this work. The obtained characteristics are used for comparative evaluations, as their bearing race dimensions are identical (see Fig. 14 for various motor illustrations).
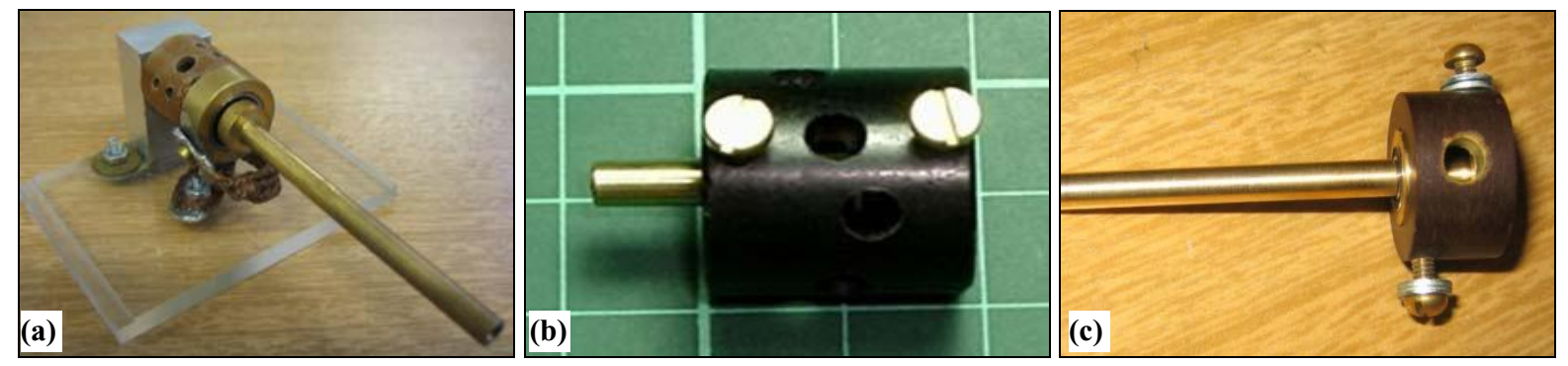

Fig. 14: (a) Existing motor built from bearings used in hard-disk. Bearings contain 9 balls each. (b) Miniature motor built from bearings used in hard-disk. Bearings contain 9 balls each. (c) Micromotor built from bearings used in a dentistry drill. Bearings contain 7 balls each.

With the Huber motor's power supply and all the three ball bearing motors constructed, burnout tests are conducted to determine the maximum operation time, for each motor, which do not affect the accuracy and integrity of the results acquired. It is determined that the shortest operating time for the two motors of the same bearing race dimensions (existing \& miniature motors, see Fig. 14(a) and (b) respectively) in kerosene with $30 \mathrm{~A}$ of current in a single run is about 57 seconds. It is therefore deduced that the data acquisition for the motor characteristics within the first 20 seconds is be appropriate. The shortest operating time for the micro motor (see Fig. 14(c)) is determined to be about 39 seconds with $6 \mathrm{~A}$ of current supplied in a kerosene bath. Therefore, the motor characteristics obtained within the first 10 seconds are appropriate.

\subsubsection{Using the DC supply}

The results in Fig. 15 show that a speed of about $8800 \mathrm{rpm}$ is achieved with $25 \mathrm{~A}$ of current for the existing motor; while the miniature motor requires only $20 \mathrm{~A}$. Alignment issues are identified as the main possible cause. The speed of the miniature motor operating in kerosene is faster, as compared to the Lauterbach motor under similar conditions. The difference in speed is more significant at lower current, but as speed increases with current, the difference between the two motors decreases. Fluctuations are noted in the speed (see Fig. 15(a) and (b) for steady-state speed of existing and miniature motors respectively) - this is likely to be due to current variations at the point contacts of the balls. The micromotor (Fig. 14c) is successful in its operation and at the same time, requires only $3 \mathrm{~A}$ to start. This result 
demonstrates that a reduction in size corresponds to lower amounts of current required (see Fig. 16 for steady-state speed of micro motor on DC supply).
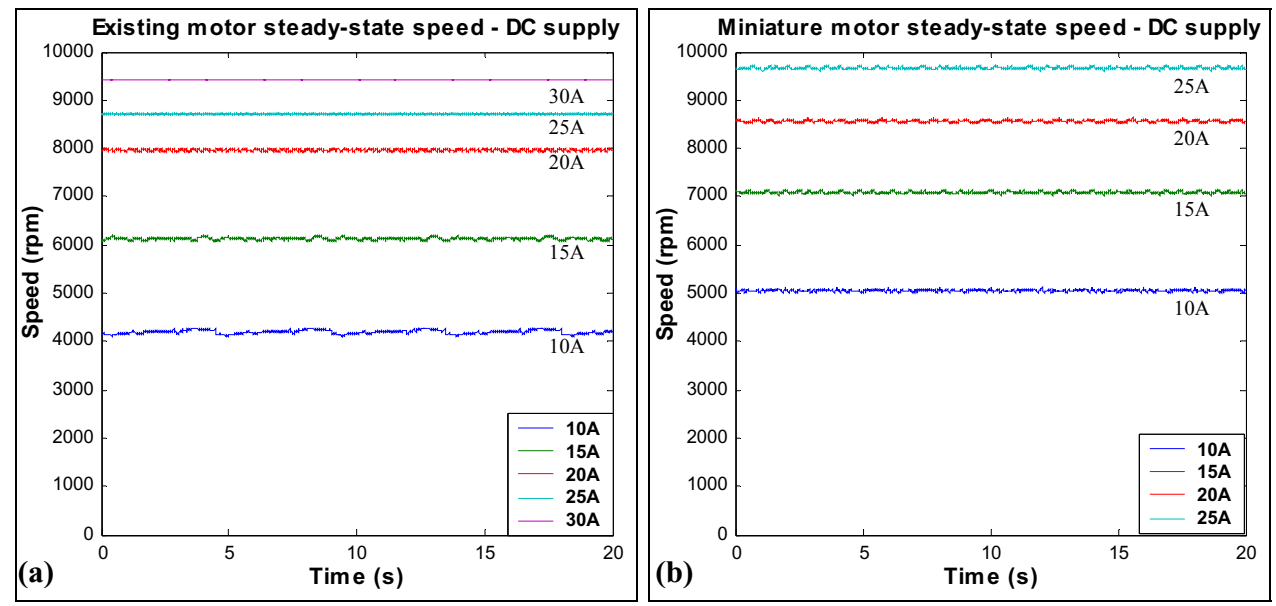

Fig. 15: (a) Steady-state speed for DC current levels ranging from 10 to 30 A. Existing motor (see Fig. 14(a)) submerged in kerosene at temperature between $23 \sim 24.2^{\circ} \mathrm{C}$. (b) Steady-state speed for DC current levels ranging from 10 to 25 A. Miniature motor (see Fig. 14(b)) submerged in kerosene at temperature between $23.2 \sim 24.1^{\circ} \mathrm{C}$. All speed data is acquired over a 20 second period.

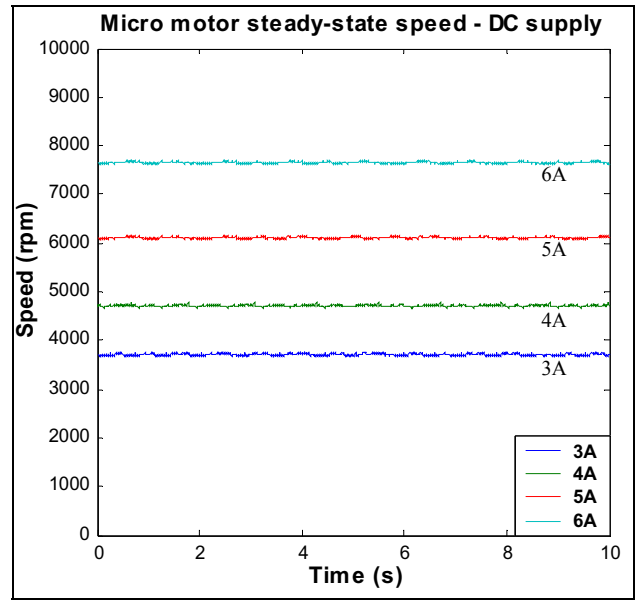

Fig. 16: Steady-state speed for DC current levels ranging from 3 to 6 A. Speed data acquired over a 10 second period. Micromotor (see Fig. 14(c)) submerged in kerosene at temperature constant between $24.1 \sim 25.3^{\circ} \mathrm{C}$.

The micromotor is operated twice without a change of bearings while maintaining all other conditions constant. The result below shows a linear relationship between speed and current and the operating speed of $2^{\text {nd }}$ run at corresponding currents is about $200 \mathrm{rpm}$ slower than the first run (see Fig. 17 for steady-state speed deviation of the micromotor on DC supply). Both motors of Figs 14a and 14b are operated twice, without a change of bearings and a linear relationship between speed and current is observed. However, a reduction in speed is also observed and this speed is about $300 \mathrm{rpm}$, at lower current for the Fig. 14a motor, and increases with increasing current. The speed deviation for the Fig. 14b motor is more consistent and a speed reduction of about $300 \mathrm{rpm}$ is observed at corresponding currents.

\subsubsection{Using the AC supply}

In earlier work, a significant number of characteristics for the motor performance were obtained using based on a DC supply source, while the use of an AC source was not considered. A lower starting speed for the Fig, 14a motor is 
observed with AC, as compared to the Fig. 14b motor in the steady-state speed test. A starting current of $10 \mathrm{~A}$ for both Fig. 14a and Fig. 14b motors results in speeds of about $2500 \mathrm{rpm}$ and $4200 \mathrm{rpm}$ respectively.

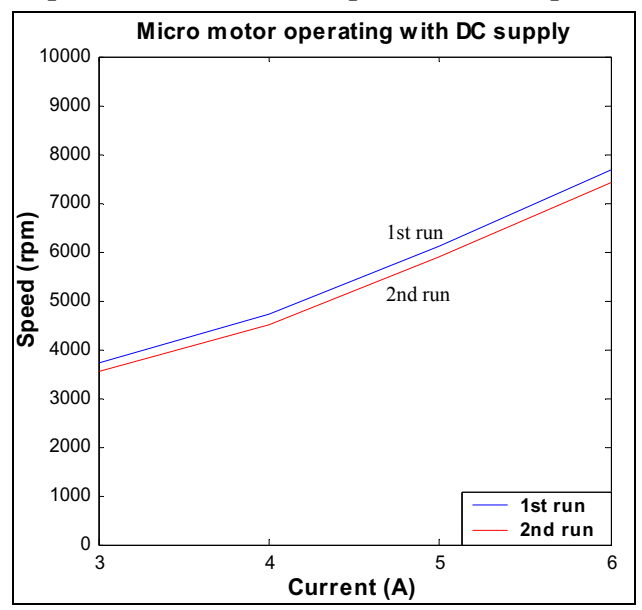

Fig. 17: Steady-state speed deviation for DC current levels ranging from 3 to $6 \mathrm{~A}$. Speed data acquired over a 10 second period for 2 runs without bearings change. The micromotor (see Fig. 14c) is submerged in kerosene at approx. constant temperature between 24.1 $\sim 25.3{ }^{\circ} \mathrm{C}$.
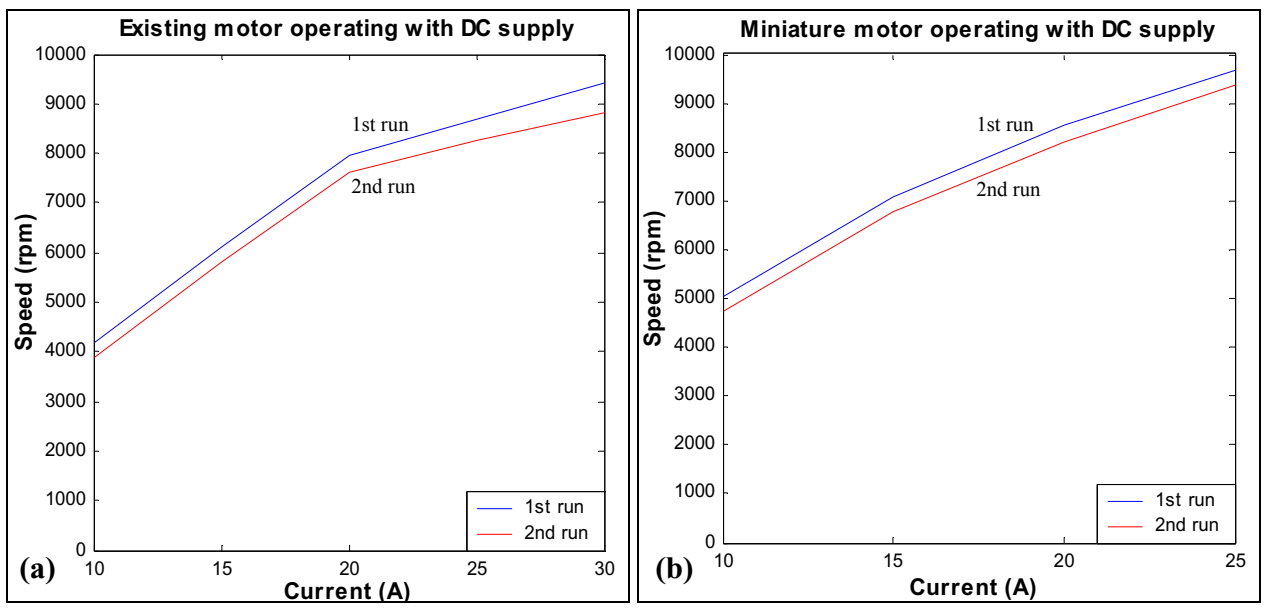

Fig. 18: (a) Steady-state speed deviation for DC current levels ranging from 10 to 30 A. Existing motor (see Fig. 14a) submerged in kerosene at temperature constant between $23 \sim 24.7^{\circ} \mathrm{C}$. (b) Steady-state speed deviation for DC current levels ranging from 10 to 25 A. Miniature motor (see Fig. 14b) submerged in kerosene at temperature constant between $23.2 \sim 24.6{ }^{\circ} \mathrm{C}$. All speed data acquired over a 20 second period for 2 runs without change of bearings.

Refined construction process and rectification of alignment issues are identified as main reasons for the large deviation of speed between these motors. The steady-state speeds for both motors are illustrated in Fig. 19. The Fig. 14c micromotor, when subjected to AC supply power, exhibits lower speeds at various currents, as compared to speed characteristics with DC power. The result also shows a fairly linear change of speed according to a change in current applied to the motor (see Fig. 20 for micromotor steady-state speed on AC supply).

The micromotor after completing initial speed tests is put to the same test again without a change of bearings, while maintaining environmental constant conditions. The speed of the $2^{\text {nd }}$ run almost coincides with that from the initial run. This would imply that the bearings are not subjected to severe degradation, as observed for the DC powered case (see Fig. 21 for speed deviation). The speed deviations for both Fig. 14a and Fig. 14b motors, without changing bearings, with an AC supply are less apparent compared to those on a DC supply (see Fig. 18). The speed deviation for the Fig. $14 \mathrm{~b}$ motor on AC supply is almost non-existent as the speed curve for the $2^{\text {nd }}$ run is in identical to initial run 

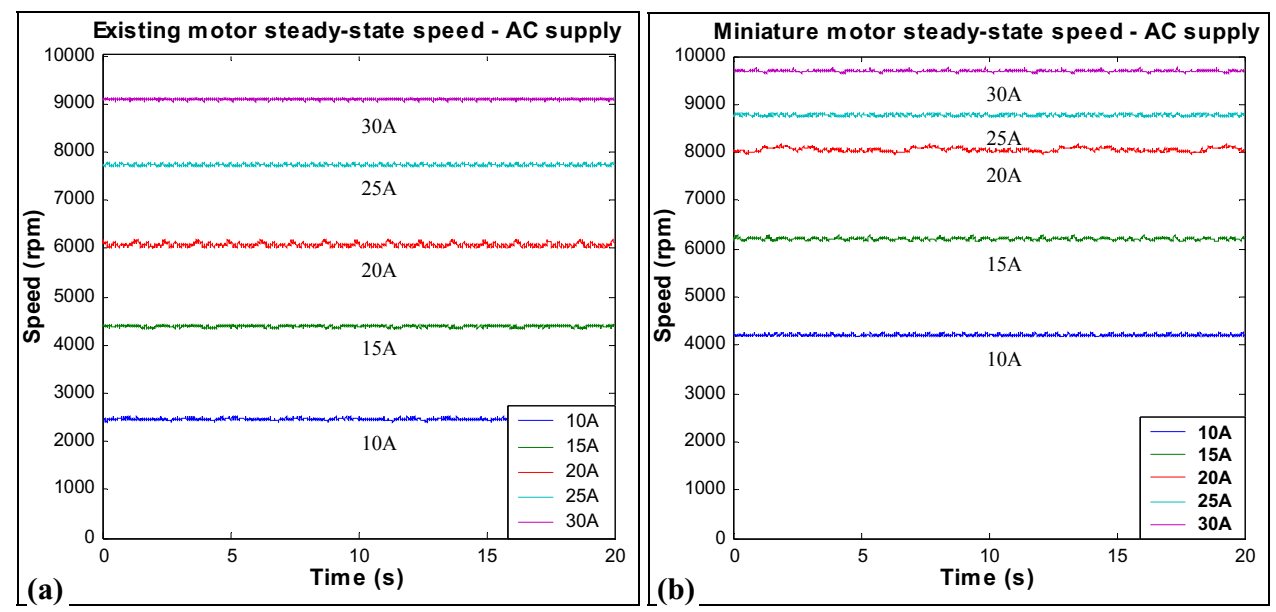

Fig. 19: (a) Steady-state speed for AC current levels ranging from 10 to $30 \mathrm{~A}$. Existing motor (see Fig. 14a) submerged in kerosene at temperature constant between $24.1 \sim 25.7^{\circ} \mathrm{C}$. (b) Steady-state speed for AC current levels ranging from 10 to 30 A. Miniature motor (see Fig. 14b) submerged in kerosene at const. temp. between $24.2 \sim 25.3^{\circ} \mathrm{C}$. All speed data acquired over a 20 second period.

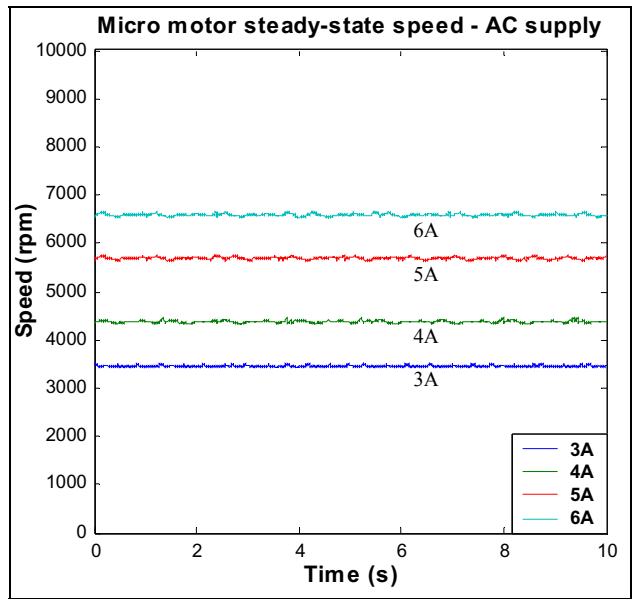

Fig. 20: Steady-state speed for AC current levels ranging from 3 to $6 \mathrm{~A}$. Speed data acquired over a 10 second period. Micromotor (see Fig. 14c) submerged in kerosene at approx. constant temperature between $24.1 \sim 25.3^{\circ} \mathrm{C}$.

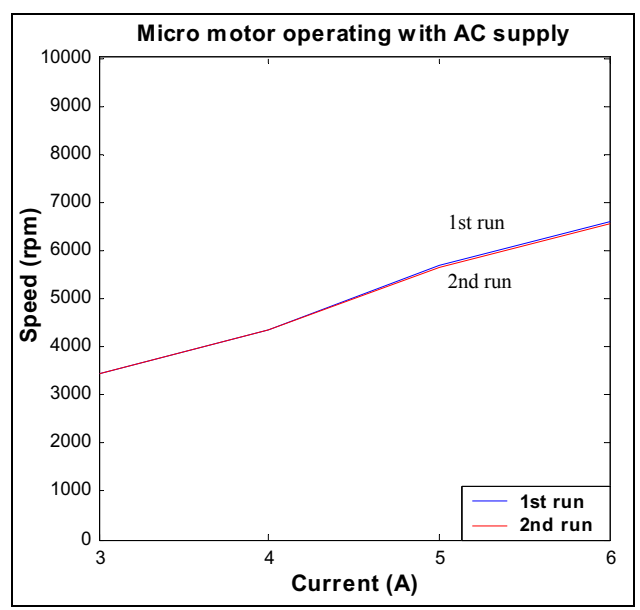

Fig. 21: Steady-state speed deviation for AC current levels ranging from 3 to 6 A. Speed data acquired over a 10 second period for 2 runs without bearings change. Micro motor (see Fig. 14(c)) submerged in kerosene at temperature constant between $24.1 \sim 25.3{ }^{\circ} \mathrm{C}$. 
From Fig. 18 and Fig. 22, there is an observation that the speed curve takes a dip at about the 20 A mark. The number of balls within the races could be a contributing factor to the deflection at this level of current.
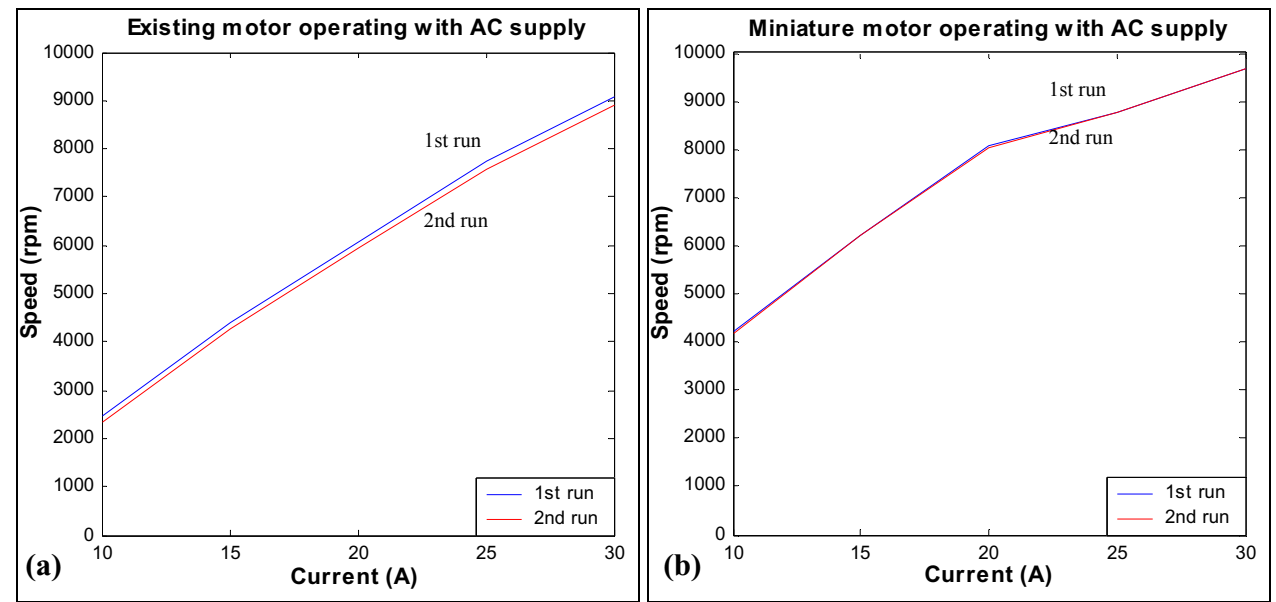

Fig. 22: (a) Steady-state speed for AC current levels ranging from 10 to 30 A. Existing motor (see Fig. 14a) submerged in kerosene at const. temp. between $23.5 \sim 24.3^{\circ} \mathrm{C}$. (b) Steady-state speed for AC current levels ranging from 10 to 30 A. Miniature motor (see Fig. 14b) submerged in kerosene at temperature constant between $23.7 \sim 24.2^{\circ} \mathrm{C}$. All speed data acquired over a 20 second period.
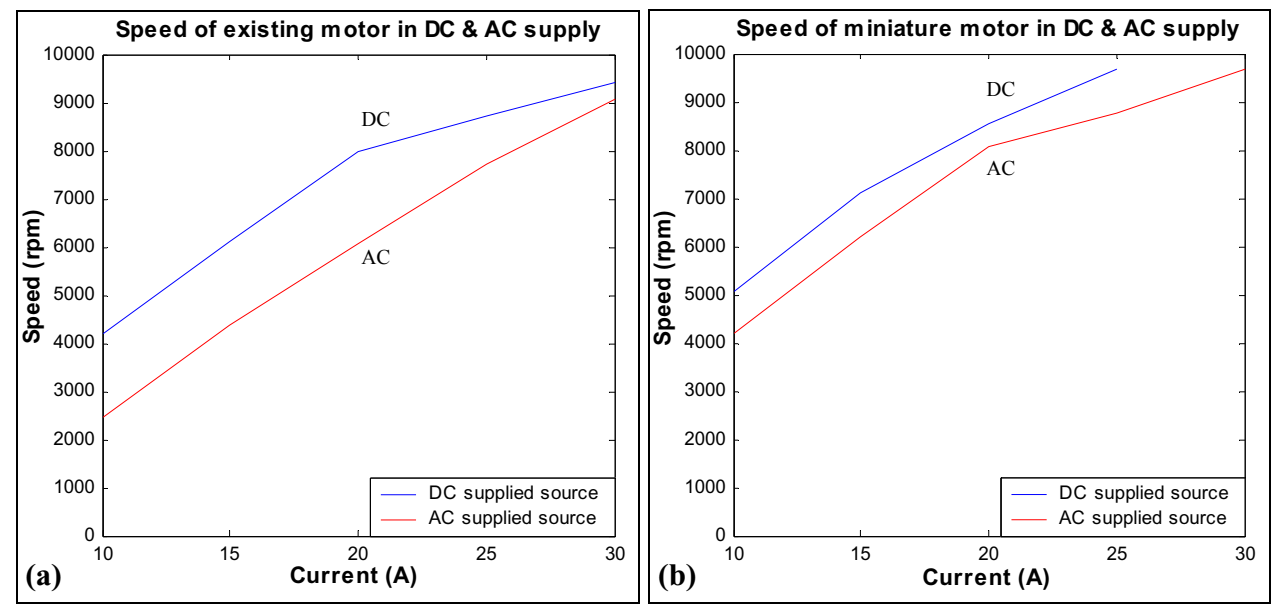

Fig. 23: (a) Speed for both DC \& AC current levels ranging from 10 to 30 A. Existing motor (see Fig. 14(a)) submerged in kerosene at temperature constant between $23 \sim 24.7^{\circ} \mathrm{C}$. (b) Speed for both DC \& AC current levels ranging from 10 to 30 A. Miniature motor (see Fig. 14(b)) submerged in kerosene at temperature constant between $23.2 \sim 24.3{ }^{\circ} \mathrm{C}$.

4.3.3. Comparing both DC and AC supplies

Comparisons of speeds achieved by both DC and AC supplies show that the speed for AC is of lower value than in the DC case. This observation is valid for all three motors placed under test. The speed deviation for different supply sources used is greater in existing motor than in the miniature motor. The speed at starting current was higher in the miniature motor for both DC and AC supplies applied. This is expected due to the correction of a major misalignment issue in the construction of the ball bearing motor. Linear relationships between speed and current were observed for all three motors on both DC and AC supply. This is in sync with practical findings established by Watson, et $a l^{10}$ and does not bear any resemblance to the square law expression for the speed-current characteristic mentioned by Gruenberg ${ }^{3}$. Current findings further support the reduction in motor dimensions resulted in lesser amount of current required, as established by Watson, et $a l^{10}$. 


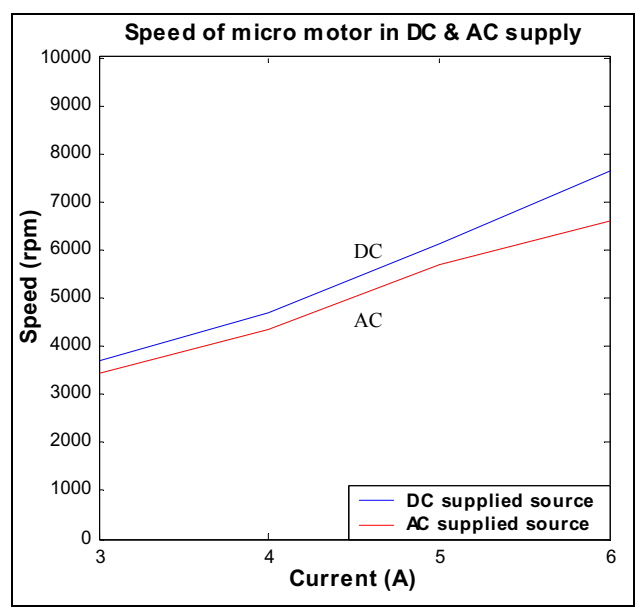

Fig. 24: Speed for both DC \& AC current levels ranging from 3 to 6 A. Micromotor submerged in kerosene at temperature constant between $24.1 \sim 25.3{ }^{\circ} \mathrm{C}$.

\subsection{Degradation of ball bearings}

The condemned ball bearings are observed under a Scanning Electron Microscope. Observations are made to the balls based on polarities for DC source, while AC is position-based (see Fig. 27).
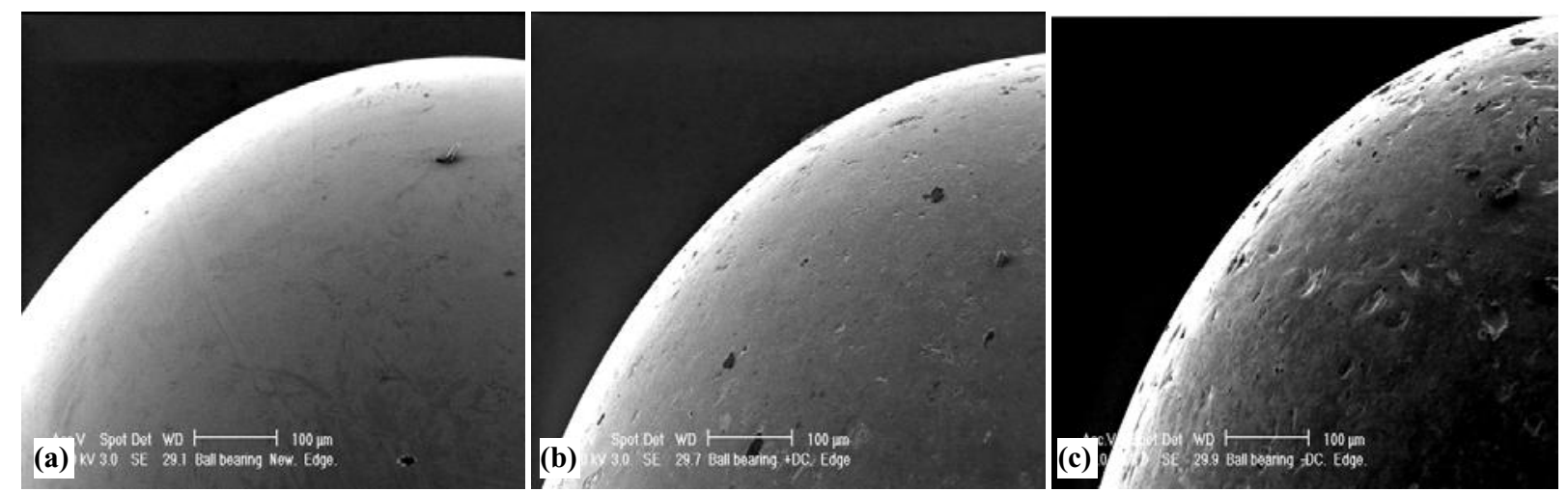

Fig. 25: (a) New bearing. Smooth surface. (b) Bearing at positive DC terminal. Roughened surface compared to new bearing surface. (c) Bearing at negative DC terminal. Significant pitting observed on surface.

It is observed that the ball bearing at the negative DC terminal have more pitting than that at the positive DC terminal (see Fig. 25b and c). On the contrary, the ball bearings on AC supply do not result in pitting, but instead produce a layer of carbon on the surface of the bearings (see Fig. $26 \mathrm{~b}$ and c).

The bearing positioned at the top of motor, in the AC case, has stream-like carbon deposited on the surface of the bearing, whereby an uneven layer of carbon deposits is observed on the surface of the bearing positioned at the bottom of the motor. The existence of carbon deposits on the bearings allows better conductivity between the races and ball, and this deposition of carbon might serve as a form of shield for the surface of the bearings against pitting. This could contribute to the fact that the motor characteristics, operating with an AC supply, have a higher repeatability. The compositional breakdown of deposits on the surface of the bearing on an AC supplied motor, is analyzed. From the breakdown analysis, relatively high carbon content is found present in the deposits (see Fig. 28). 

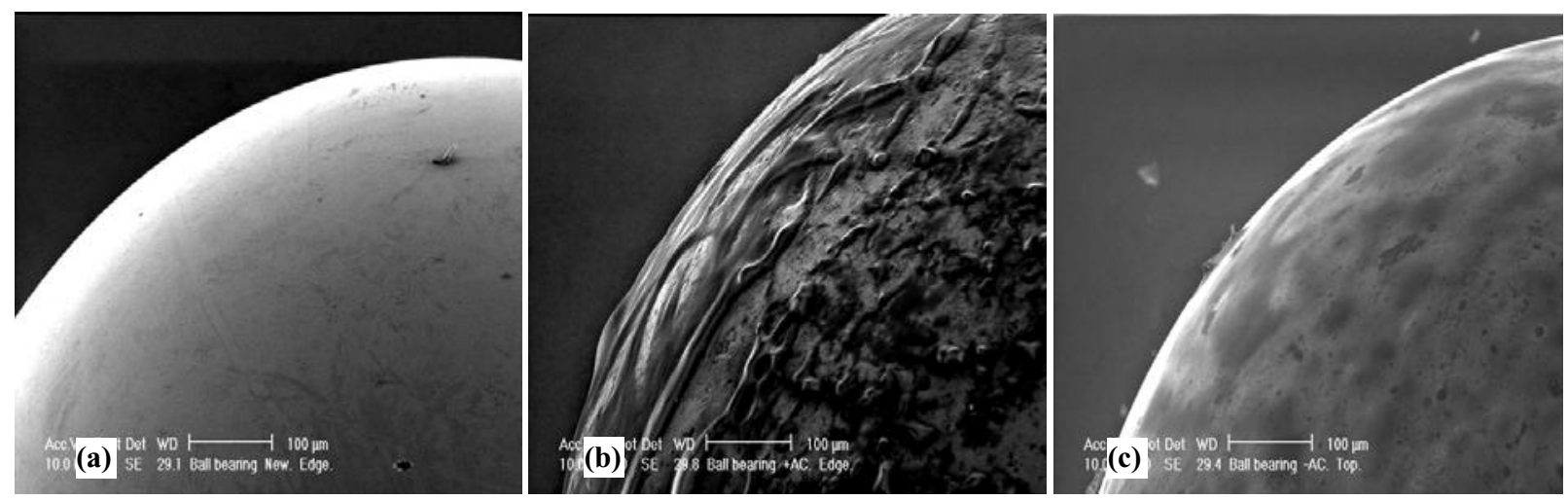

Fig. 26: (a) New bearing. Smooth surface. (b) Bearing at top of motor. Surface coated with stream-like carbon. (c) Bearing at bottom of motor. Surface coated with layer of carbon. No obvious pitting.
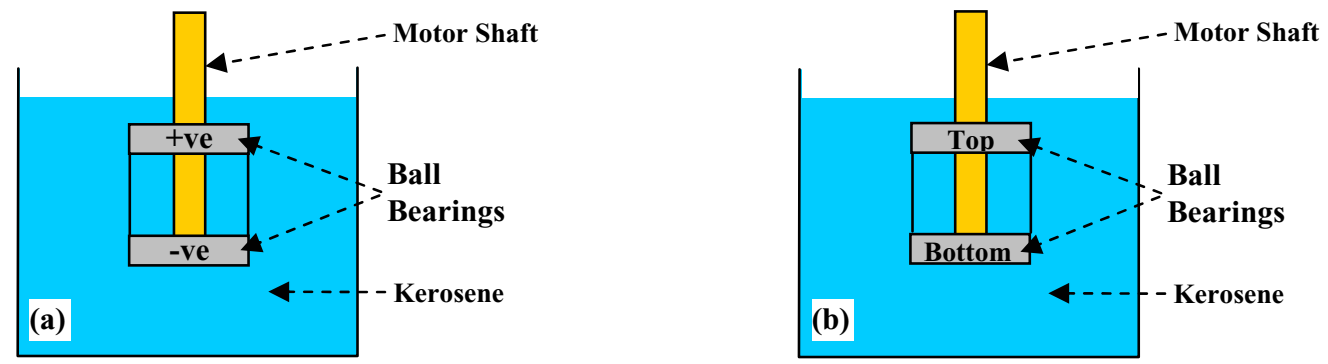

Fig. 27: (a) Illustration of positive \& negative ends of DC source supplied miniature motor (see Fig. 14b). (b) Illustration of top \& bottom placement of AC source supplied miniature motor (see Fig. 14b).

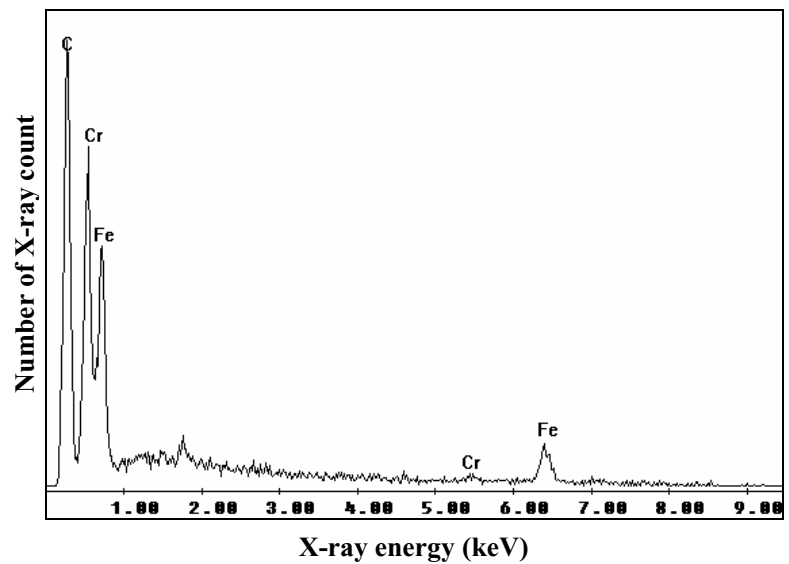

Fig. 28: Compositional breakdown of deposits found on surface of bearings on an AC supplied Huber motor.

\subsection{Torque characteristics}

Frictional torque of the Huber motor is determined using the method identified in Section 3.3. With the characteristics of the DC machine evaluated, the Huber frictional torque, which includes bearing friction and liquid drag, is determined. The Huber motor is put through a series of operations, with a DC supply, and the resulting frictional torque is determined. A fresh set of bearings is used and the initial Huber frictional torque is again evaluated. Another series of motor operations, with an AC supply, is conducted, and the resulting frictional torque is determined for comparisons. 


\subsubsection{Existing motor}

The Huber frictional torque is the difference between the conventional DC motor with no load torque and DC motor with inactive load. The inactive load, here, refers to the Huber motor attached to the DC motor, without putting any current through it (see Fig. 29 for Frictional Torque before and after operations on DC supply).
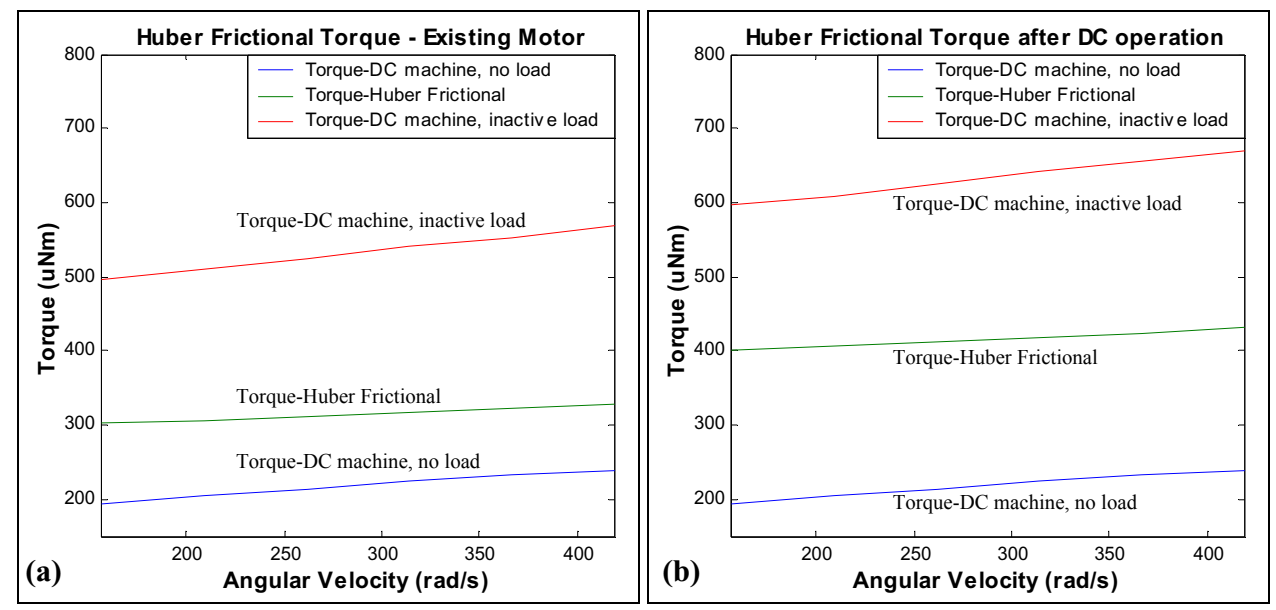

Fig. 29: (a) Huber frictional torque on new set of bearings in existing motor (see Fig. 14(a)). (b) Huber frictional torque determined, with existing motor (see Fig. 14a) was subjected to DC.

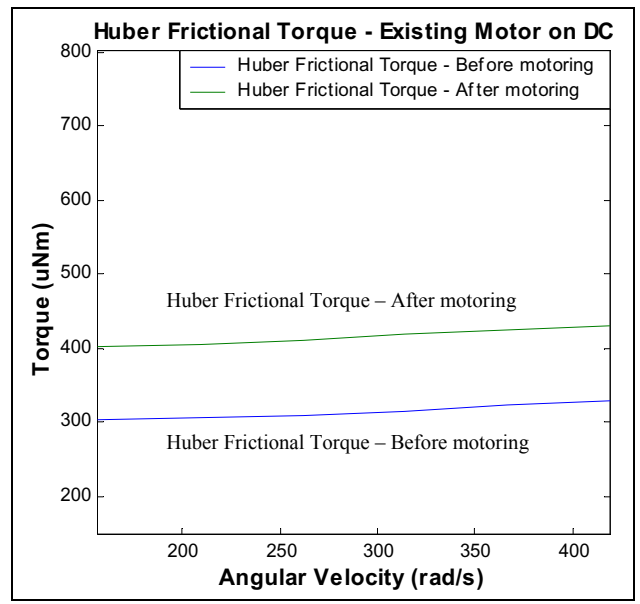

Fig. 30: Deviation of Huber frictional torque in existing motor (see Fig. 14a). Frictional torque increases by about $100 \mu N m$ after motor operation with DC supply.

In Fig. 30, an observation of about a $100 \mu \mathrm{Nm}$ increment in frictional torque is made for the existing motor after use with a DC supply. This implies that the bearings, after going through a series of DC motori operations, have degraded resulting in the increased frictional torque. The increment of frictional torque after motor operations on an AC supply is about $78 \mathrm{uNm}$. This increment is less than the value evaluated after DC operation. The possibility of this could be due to the layer of carbon deposition observed on the surface of the bearings (see Section 4.4). The layer of carbon may have shielded the bearing from severe pitting. In Fig. 32, linear relationships were observed for torque against angular velocity and current respectively. This finding supports the practical finding established by Watson, et $a l^{10}$ for a linear relationship between torque developed and the current supplied. Similar linear relationships between torque against angular velocity and current are observed in Fig. 33 respectively for the existing motor operating with an AC supply. These results showed that a DC or AC supply has no direct impact on the linearity of the torque against angular velocity or current. 


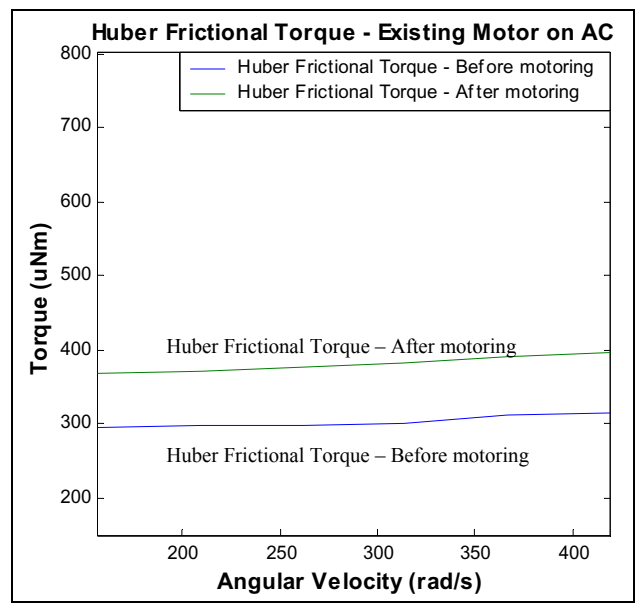

Fig. 31: Deviation of Huber frictional torque in existing motor (see Fig. 14a). Frictional torque increased about $78 \mu \mathrm{Nm}$ after motori operation on an AC supply.
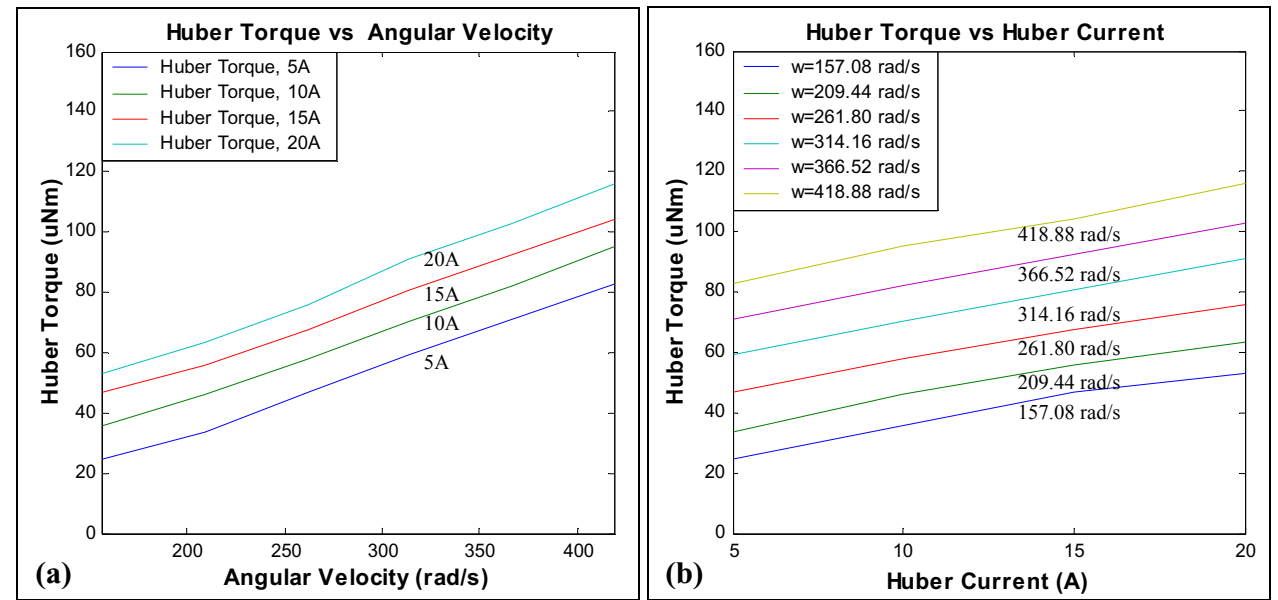

Fig. 32: (a) Huber Torque of existing motor (see Fig. 14a) generated in the form of assistance to the DC machine on DC supply for angular velocity ranging from $150 \sim 420 \mathrm{rad} / \mathrm{s}$. (b) Huber Torque of existing motor (see Fig. 14a) generated in the form of assistance to the DC machine on DC supply for Huber current ranging from $5 \sim 20 \mathrm{~A}$.
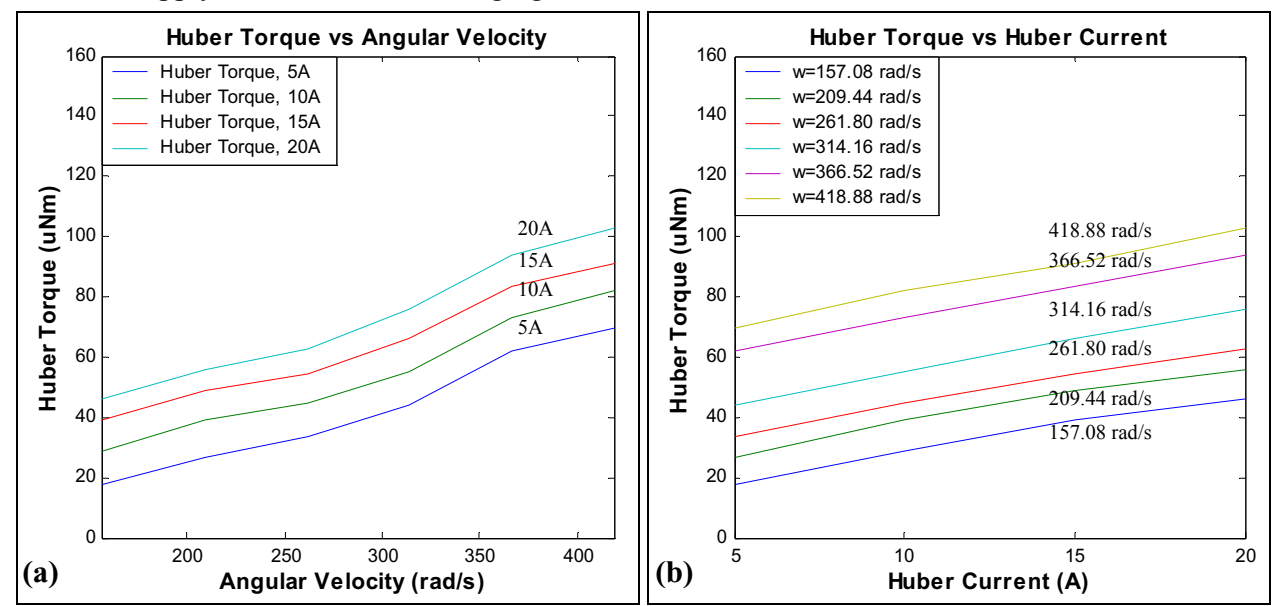

Fig. 33: (a) Huber torque of existing motor (see Fig. 14a) generated in the form of assistance to the DC machine on AC supply for angular velocity ranging from $150 \sim 420 \mathrm{rad} / \mathrm{s}$. (b) Huber Torque of existing motor (see Fig. 14a) generated in the form of assistance to the $\mathrm{DC}$ machine on $\mathrm{AC}$ supply for Huber current ranging from $5 \sim 20 \mathrm{~A}$. 


\subsubsection{Miniature motor}

Tests conducted in the preceding section are repeated in the exact manner for the miniature motor. From the results obtained, it is clear that the change in friction for the motor is more significant for the motoring operation conducted on DC supply than on the AC supply. The deposition of carbon could be the determining factor that resulted in this observation. It is also observed that the frictional torque at both before and after motor operations are lower for the miniature motor (see Fig. 14b) as compared to the existing motor (see Fig. 14a). The most likely reason for this observation is due to the correction in the alignment for the assembly of the miniature motor.
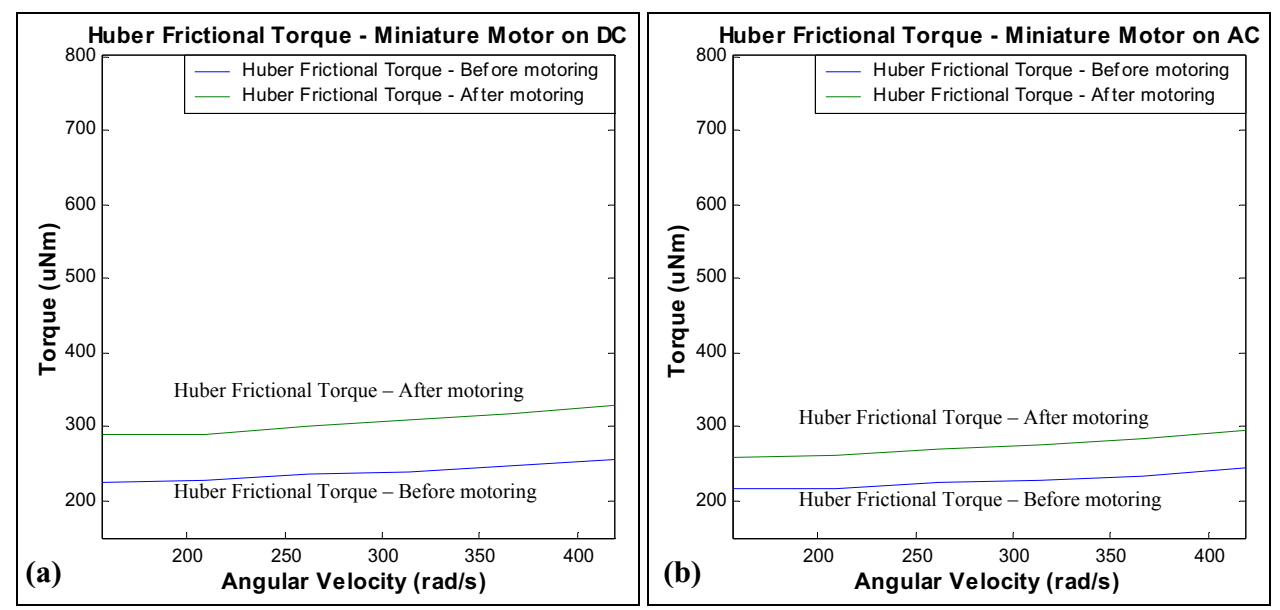

Fig. 34: (a) Deviation of Huber frictional torque in miniature motor (see Fig. 14b). Frictional torque increased about $70 \mu \mathrm{Nm}$ after motoring operation on DC supply. (b) Deviation of Huber Frictional Torque in miniature motor (see Fig. 14b). Frictional torque increased about $50 \mu \mathrm{Nm}$ after motoring operation on AC supply.

For Fig. 35a, the linear change in torque is about $10 \mu \mathrm{Nm}$ for every angular velocity ranging from $150 \sim 420 \mathrm{rad} / \mathrm{s}$. A linear relation is also observed for torque change supplied current to the motor (see Fig. 35b).
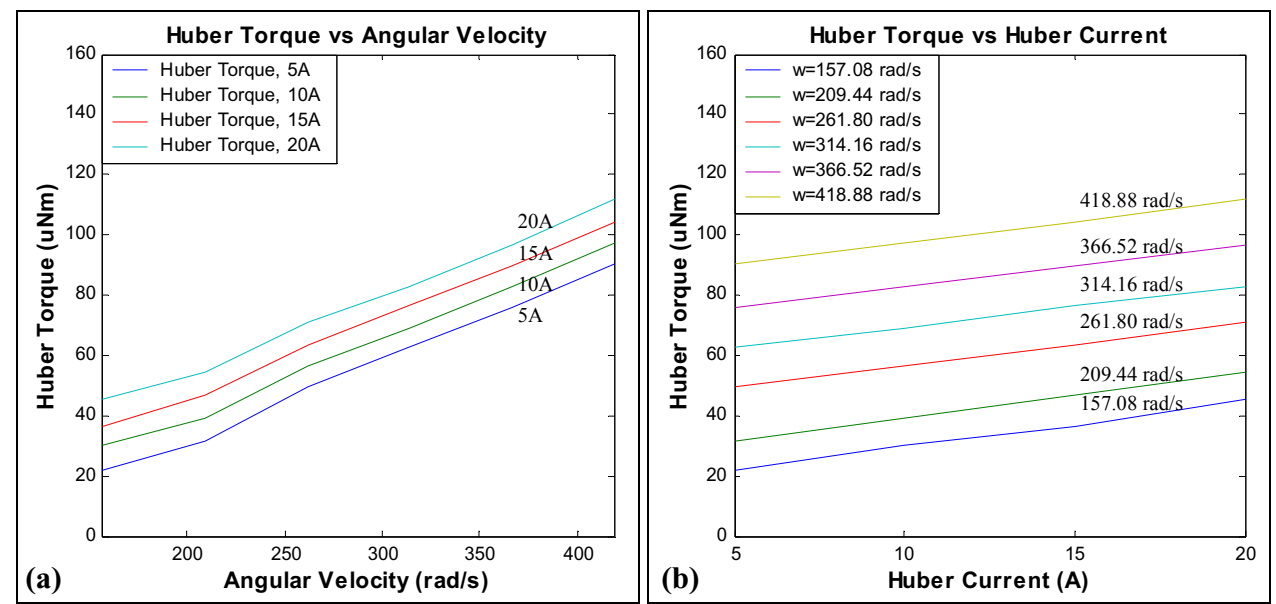

Fig. 35: (a) Huber torque of miniature motor (see Fig. 14b) generated in the form of assistance to the DC machine on DC supply for angular velocity ranging from $150 \sim 420 \mathrm{rad} / \mathrm{s}$. (b) Huber Torque of miniature motor (see Fig. 14b) generated in the form of assistance to the DC machine on DC supply for Huber current ranging from $5 \sim 20 \mathrm{~A}$.

Similar linear relations were observed for torque change against angular velocity and current for motoring achieved on AC supply. A lower value of torque occurred for AC supplied motoring than in DC (see Fig. 36 for torque produced on AC supply). 

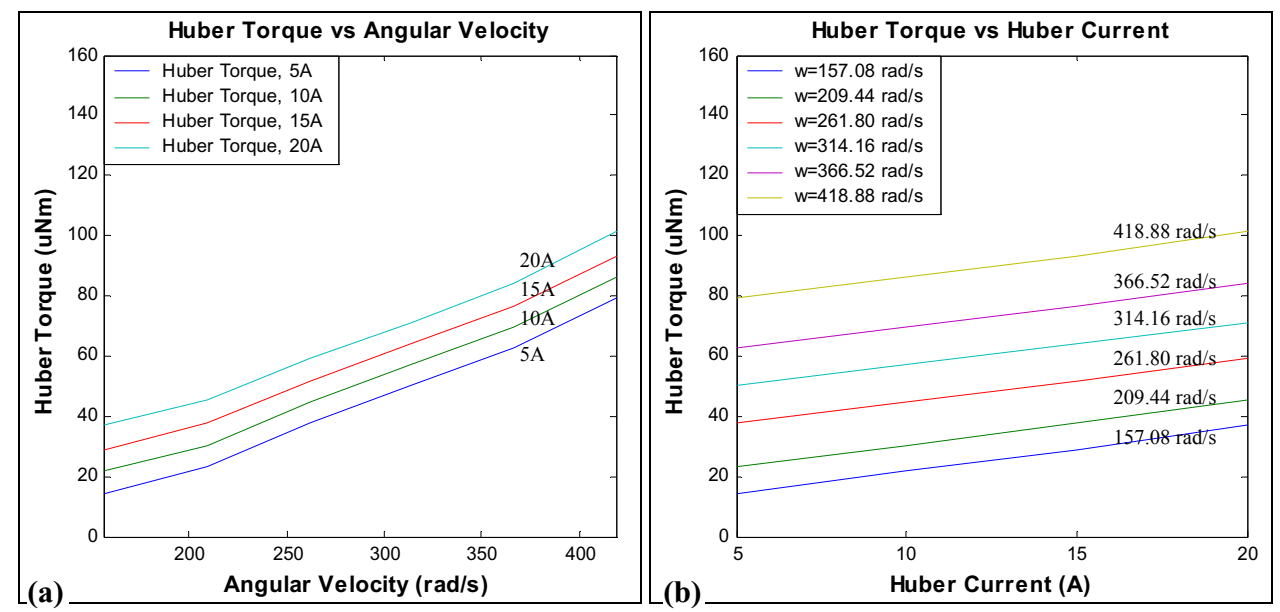

Fig. 36: (a) Huber Torque of miniature motor (see Fig. 14(b)) generated in the form of assistance to the DC machine on AC supply for angular velocity ranging from $150 \sim 420 \mathrm{rad} / \mathrm{s}$. (b) Huber Torque of miniature motor (see Fig. 14(b)) generated in the form of assistance to the DC machine on AC supply for Huber current ranging from $5 \sim 20 \mathrm{~A}$.

\section{CONCLUSION}

Both DC and AC supply power for Huber motor operation permitted a comparative evaluation. The results show that higher speeds are achieved with DC, as compared to AC. However, it also shown that an AC source resulted in higher repeatability than with DC, due to lesser degradation of the balls with AC. Both DC and AC sources gave rise to fairly linear relationships between current and speed. The design and development of a new ball bearing motor enhanced operation sustainability, and most importantly, repeatability in the conduct of experiments. The reduction of motor size is achieved, with correspondingly lower operational current. Our findings support the linear relationships between speed and current, suggested by Watson, et $a l^{10}$. This current work and that of Watson, et al. ${ }^{10}$ refutes the square-law expression established by Gruenberg ${ }^{3}$.

\section{ACKNOWLEDGEMENTS}

The authors would like to thank the technical staff from School of Electrical and Electronic Engineering, especially Ian Linke, Stuart Brandt and Brad Pullen for their valuable guidance and assistance. The construction of various ball bearing prototypes would not be possible without their technical expertise. The assistance from Tiong Jingren and Lim Hong Hoo in the set up was much appreciated by the authors. The authors would also like to thank the staff from our electron microscopy center.

\section{REFERENCES}

1 J. Huber, "Electrodynamische Kraftwirkungen au Einem auf Eisinbahschienen Beweglichen Radsatz," Elektrotechnik und Maschinebau, vol. 76, pp. 169-74, 1959.

2 R. A. Milroy, "Hydrodynamic gyroscope," Journal of Applied Mechanics, vol. 34, pp. 525, 1967.

3 H. Gruenberg, "The ball bearing as a motor," American Journal of Physics, vol. 46, pp. 1213-9, 1978.

4 A.P. Lauterbach, W. L. Soong and D. Abbott, "Investigation of small motors operating under the Huber effect," Proceedings of SPIE, vol. 4236, pp. 306-18, 2001.

5 M. P. H. Weenink, "The electromagnetic torque on axially symmetric rotating metal cylinders or spheres," Applied Scientific Research, vol. 37, pp. 171-82, 1981.

6 P. G. Moyssides, "Electrical Characteristics of Two Discs Operating as a Motor," IEEE Transactions on Magnetics, vol. 28, No. 3, pp. 1870-6, 1992.

7 P. G. Moyssides and P. Hatzikonstantinou, "Study of electrical characteristics of the ball bearing motor," IEEE Transactions on Magnetics, vol. 26, No. 4, pp. 1274-81, 1990.

8 P. G. Moyssides and P. Hatzikonstantinou, "Ball bearing motors," IEEE Transactions on Magnetics, vol. 33, No. 6, pp. 4566-9, 1997. 
9 P. G. Moyssides and P. Hatzikonstantinou, "Explanation of the ball bearing motor and exact solutions of the related Maxwell equations," Journal of Physics A: Math. Gen., vol. 23, pp. 3183-97, 1989.

10 D. B. Watson, M. R. Williams and C. S. Crimp, "Ball-bearing motors," IEE Proceedings- $A$, vol. 140, no. 4, pp. 281-6, 1993.

11 S. Marinov, "The intriguing ball-bearing motor," Electronics \& Wireless World, pp. 356-7, April 1989.

12 K. M. Polivanov, A. V. Netushil and N. V. Tatarinova, "Electromechanical effect of Huber," Elektrichestvo, No. 8, pp. 72-6, 1973.

13 V. Netushil, "The electromechanical effect of Huber and its development," Electrical Technology, No. 3, pp. 57-64, 1992.

14 B. Thompson, Y. Shen, B. K. Tay, W. L. Soong, B. R. Davis and D. Abbott, "Investigation of the Huber effect and its application to micromotors," Proceedings of SPIE Electronics and Structures for MEMS, vol. 3891, pp. 178-83, 1999.

15 S. A. Boctor, P. F. Ryff, P. D. Hiscocks, M. T. Ghorab, M. R. Holmes, Electrical Concepts and Applications", West Publishing, Minneapolis, 1997. 